\title{
Deskripsi ketinggian korpus mandibula melalui arsip radiografi digital panoramik pada pasien di RSGM Unpad
}

\author{
Icha Putri ${ }^{1}$, Ria Noerianingsih Firman ${ }^{2 *}$, Moch Rodian $^{3}$
}

\section{ABSTRACT}

Objectives: The purpose of this study is to obtain measurements of dentate and edentulous corpus mandibulae height on RSGM Unpad patients through digital panoramic radiograph.

Material and Methods: This research is using descriptive method. Population in this research is digital panoramic radiograph from RSGM Unpad patient's database. The technique used is purposive sampling, and obtained 50 panoramic digita panoramic radiograph samples.

${ }^{1}$ Program Studi Pendidikan Dokter Gigi, Fakultas Kedokteran Gigi, Universitas Padjadjaran, Bandung, Indonesia, 40132

2Departemen Radiologi Kedokteran Gigi, Fakultas Kedokteran Gigi, Universitas Padjadjaran, Bandung, Indonesia, 40132

${ }^{3}$ Departemen Oral Biologi, Fakultas Kedokteran Gigi, Universitas Padjadjaran, Bandung, Indonesia, 40132

*Correspondence to:

Ria Noerianingsih Firman

凶ria.firman@fkg.unpad.ac.id

Received on: June 2019

Revised on: July 2019

Accepted on: August 2019 (2):21-5. https://doi.org/10.32793/jrdi.v3i2.486

\section{PENDAHULUAN}

Radiografi merukapan modaliti penunjang pemeriksaan pasien dalam menegakkan diagnosa dan rencana perawatan karena dinilai dapat memberikan informasi mengenai struktur oral yang tidak terlihat secara kasat mata. Salah satu teknik radiografi yang sering digunakan adalah radiografi panoramik (pantomography). Radiografi panoramik merupakan radiograf yang menampilkan gambaran luas struktur fasial yang meliputi arkus maksila dan mandibula beserta seluruh struktur pendukungnya. ${ }^{1}$ Gambaran normal meliputi areal geligi, hidung, sinus, mandibula, sendi temporomandibula, spina dan ramus, hyoid dan juga areal mandibula. Mandibula secara umum terbagi menjadi bagian ramus dan korpus. ${ }^{2.3}$ Korpus biasa disebut badan mandibula, merupakan tempat tertanamnya gigi geligi rahang bawah dengan segala struktur pendukungnya. Gupta dan Jain pada tahun 2012 menyatakan bahwa radiograf panoramik dapat memberikan informasi adekuat untuk perhitungan vertikal (ketinggian) mandibula. ${ }^{4}$ Ketinggian mandibula dapat dihitung pada rahang bergigi dan rahang tidak bergigi. Menurut Canger dan Celenk, 2012 ketinggian rahang bergigi adalah jarak dari 2 milimeter diatas CEJ bagian distal gigi sampai tepi inferior mandibula dan ketinggian rahang tidak bergigi adalah jarak dari puncak tulang residual sampai tepi inferior mandibula. ${ }^{5}$
Results: The results shows the highest dentate corpus mandibulae height is in men $38,1 \mathrm{~mm}$ age 65 -85 on left side of corpus and the highest edentulous corpus mandibulae height is in men 26,3 mm age 55 -64 on right side of corpus.

Conclusion: To summarize, the highest dentate corpus mandibulae height on the right side is in men age 45-54, on the left side is in men age 65-85, the highest edentulous corpus mandibulae on the right and left side is in men age 55-64, and overall corpus mandibulae height on the right and left side on women is lower than men in all ages.

Keywords: Corpus mandibulae height, radiograph, digital panoramic

Cite this article: Putri I, Firman RN, Rodian M. Deksripsi ketinggian korpus mandibula melalui arsip radiografi digital panoramik pada pasien RSGM Unpad. Jurnal Radiologi Dentomaksilofasial Indonesia 2019;3

Ketinggian korpus mandibula pada tiap orang bervariasi, bergantung kepada tingkat resorbsi tulang alveolar yang dipengaruhi oleh beberapa faktor diantaranya: kehilangan tulang periodontal, ekstraksi gigi, hormon, dan penggunan protesa lepasan dalam jangka panjang. ${ }^{6}$ Resorbsi tulang dapat dipengaruhi oleh faktor lokal dan faktor sistemik, seperti usia, luka traumatik, kondisi patologis, kelainan metabolisme, osteoporosis, hiperparatiroidisme, dan ketidakseimbangan hormon, selain itu resorbsi sangat berhubungan dengan penggunaan protesa. Resorbsi pada mandibula lebih besar dibandingkan maksila dikarenakan tekanan yang diterima lebih banyak karena permukaan kontak dengan jaringan lunak supportive yang lebih sedikit, terutama pada regio gigi premolar dan molar karena reversal line lebih rendah. ${ }^{7,8}$ Reversal line merupakan garis batas resorbsi tulang dan area formasi tulang yang baru (batas antara area alveolar dengan basal). Selain itu, pada bagian lingual anterior mandibula terdapat perlekatan otot genial, dimana perlekatan tersebut melindungi dari kehilangan tulang alveolar dan resorbsi vertikal. Setelah terjadi resorbsi secara fisiologis, struktur tulang rahang yang tinggal disebut dengan tulang residual. ${ }^{7,8}$

Permasalahan gigi dan mulut yang sering terjadi adalah kehilangan gigi. Salah satu syarat yang harus 
dipenuhi dalam perawatan gigi adalah ketinggian tulang rahang yang adekuat, apabila tidak maka perlu dilakukan bedah preprostetik. ${ }^{7}$ Massa dan kekuatan tulang yang rendah memengaruhi prognosa perawatan gigi, contohnya pada dental implan, augmentasi linggir, dan protesa cekat dan lepasan. ${ }^{9}$ Ketinggian tulang tiap orang berbeda yang dimungkinkan karena laju resorbsi setiap individu berbeda. Ketinggian tulang ini dapat diperkirakan atau dinilai dengan menggunakan teknik radiograf panoramik. $^{8} \quad$ Radiograf panoramik memberikan informasi mengenai resorbsi dan pembentukan tulang. Perkiraan mengenai ketinggian tulang memengaruhi prognosis, rencana perawatan protesa, dan estetika. ${ }^{10}$ Radiograf panoramik yang digunakan dalam prosedur perawatan gigi dapat digunakan dalam semua tahap, yaitu rencana perawatan, operasi, fase penyembuhan, dan evaluasi. ${ }^{11}$ Tujuan dari penelitian ini adalah mendapatkan ukuran ketinggian korpus mandibula di RSGM Unpad melalui arsip radiograf panoramik digital.

\section{BAHAN DAN METODE}

Jenis penelitian yang digunakan dalam penelitian ini adalah deskriptif. Populasi dalam penelitian ini adalah 4918 radiograf panoramik digital pasien Rumah Sakit Gigi dan Mulut Universitas Padjadjaran, dengan sampel 50 radiograf, yaitu 30 arsip radiograf korpus mandibula bergigi dan 20 arsip radiograf korpus mandibula tidak bergigi, dimana 23 arsip radiograf laki-laki dan 27 arsip radiograf perempuan. Sampel dipilih dengan metode purposive random sampling dengan dengan kriteria: 1) Pada radiograf dengan korpus mandibula untuk pasien bergigi: radiograf dengan permukaan oklusal gigi yang masih baik, radiograf dengan minimal 20 gigi ( 2 gigi anterior tiap rahang dan 2 gigi posterior tiap rahang pada sisi kanan dan kiri) dan usia pasien rentang 45 sampai 85 tahun; 2) Pada radiograf dengan korpus mandibula untuk pasien tidak bergigi: Radiograf dengan puncak linggir residual dan tepi inferior mandibula yang jelas dan sia pasien rentang 45 sampai 85 tahun.

Ketinggian korpus mandibula bergigi adalah jarak dari 2 milimeter diatas CEJ bagian distal gigi sampai tepi inferior mandibula. Ketinggian korpus mandibula tidak bergigi adalah jarak dari puncak tulang residual sampai tepi inferior mandibula, dengan tepi inferior mandibula merupakan permukaan yang membentuk bagian paling bawah dari mandibula atau rahang bawah dan puncak tulang residual merupakan puncak tulang rahang tidak bergigi. Data dikumpulkan kemudian dihitung rata-rata untuk setiap kelompok sampel.

\section{HASIL}

Penelitian ini dilakukan pada tanggal 23,24 , dan 26 Juni 2015, pada arsip radiografi panoramik digital pasien pria dan wanita berusia 45 sampai 85 tahun selama periode 1 Januari 2013 sampai 31 Desember 2014. Jumlah sampel yang didapat yaitu 30 arsip radiograf mandibula bergigi dan 20 arsip radiograf mandibula tidak bergigi, dengan 23 arsip radiograf laki-laki dan 27 arsip radiograf perempuan. Penelitian ini melakukan pengukuran ketinggian korpus mandibula bergigi dan tidak bergigi pada laki-laki dan perempuan dibagi ke dalam kelompok usia 45-54 tahun, 55-64 tahun, dan 65-85 tahun yang dilakukan pada sisi kanan dan sisi kiri mandibula.

Gambar 1 menunjukkan grafik distribusi jumlah sampel untuk pengukuran ketinggian korpus mandibula bergigi dan tidak bergigi. Jumlah sampel untuk mandibula bergigi adalah 12 arsip radiograf laki-laki dan tampak 18 arsip radiograf perempuan. Jumlah sampel untuk mandibula tidak bergigi adalah 11 arsip radiograf laki-laki dan tampak 9 arsip radiograf perempuan.

\section{PENGUKURAN KORPUS MANDIBULA UNTUK PASIEN BERGIGI}

Pada Gambar 2, terlihat hasil pengukuran ketinggian korpus mandibula bergigi kelompok jenis kelamin laki-laki dan perempuan. Hasil pengukuran kelompok usia 45-54 tahun pada laki-laki sisi kanan didapat rata-rata $34.7 \mathrm{~mm}$ dan sisi kiri didapat ratarata $34.3 \mathrm{~mm}$. Pada perempuan sisi kanan didapat rata-rata $30.4 \mathrm{~mm}$ dan sisi kiri $30.3 \mathrm{~mm}$. Hasil pengukuran kelompok usia 55-64 tahun pada lakilaki sisi kanan didapat rata-rata $32.2 \mathrm{~mm}$ dan sisi kiri didapat rata-rata $31.6 \mathrm{~mm}$. Pada perempuan sisi kanan didapat rata-rata $30.0 \mathrm{~mm}$ dan sisi kiri 30.3 $\mathrm{mm}$. Hasil pengukuran kelompok usia 65-85 tahun pada laki-laki sisi kanan didapat rata-rata $33.8 \mathrm{~mm}$ dan sisi kiri didapat rata-rata $38.1 \mathrm{~mm}$. Pada

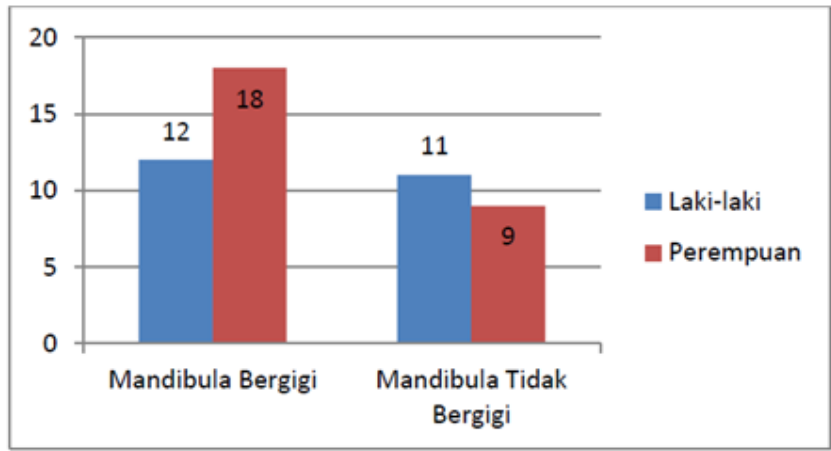

Gambar 1. Grafik distribusi sampel penelitian 




Gambar 2. Grafik hasil pengukuran ketinggian korpus mandibula pasien bergigi

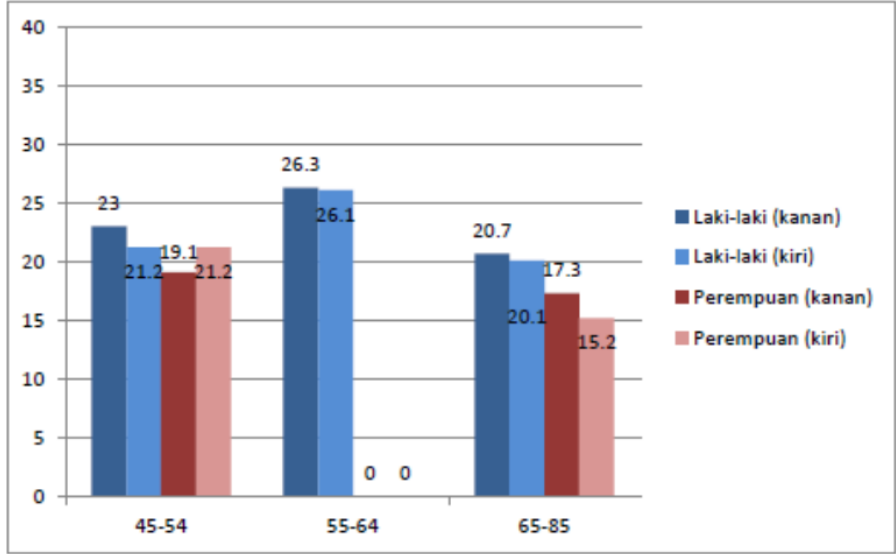

Gambar 3. Grafik hasil pengukuran ketinggian korpus mandibula pasien tidak bergigi

perempuan sisi kanan didapat rata-rata $30.3 \mathrm{~mm}$ dan sisi kiri $31.9 \mathrm{~mm}$.

Dari hasil tersebut terlihat bahwa korpus mandibula pada laki-laki paling tinggi yaitu sebesar $38,1 \mathrm{~mm}$ pada korpus mandibula sisi kiri kelompok usia 65-85 tahun dan memiliki nilai paling rendah yaitu sebesar 31,6 mm pada korpus mandibula sisi kiri kelompok usia 55-64 tahun. Terlihat korpus mandibula pada perempuan paling tinggi yaitu sebesar 31,9 mm pada korpus mandibula sisi kir kelompok usia 65-85 tahun dan paling rendah yaitu sebesar 30,0 mm pada korpus mandibula sisi kanan kelompok usia 55-64 tahun.

\section{PENGUKURAN KORPUS MANDIBULA UNTUK PASIEN TIDAK BERGIGI}

Pada Gambar 3, terlihat hasil pengukuran ketinggian korpus mandibula tidak bergigi kelompok jenis kelamin laki-laki dan perempuan. Hasil pengukuran kelompok usia 45-54 tahun pada laki-laki sisi kanan didapat rata-rata $23 \mathrm{~mm}$ dan sis kiri didapat rata-rata 21,2 $\mathrm{mm}$. Pada perempuan sisi kanan didapat rata-37 rata 19,1 $\mathrm{mm}$ dan sisi kiri 21,2 mm. Hasil pengukuran kelompok usia 55-64 tahun pada laki-laki sisi kanan didapat rata-rata $26,3 \mathrm{~mm}$ dan sisi kiri didapat rata-rata $26,1 \mathrm{~mm}$. Pada perempuan tidak didapatkan sampe pengukuran. Hasil pengukuran kelompok usia 65-85 tahun pada laki-laki sisi kanan didapat rata-rata
$20,7 \mathrm{~mm}$ dan sisi kiri didapat rata-rata $20,1 \mathrm{~mm}$. Pada perempuan sisi kanan didapat rata-rata 17,3 $\mathrm{mm}$ dan sisi kiri 15,2 $\mathrm{mm}$.

Dari hasil tersebut terlihat bahwa korpus mandibula pada laki-laki paling tinggi yaitu sebesar 26,3 $\mathrm{mm}$ pada korpus mandibula sisi kanan kelompok usia 55-64 tahun dan nilai paling rendah yaitu sebesar 20,1 mm terdapat pada korpus mandibula sisi kiri kelompok usia 65-85 tahun. Korpus mandibula pada perempuan paling tinggi yaitu sebesar $21.2 \mathrm{~mm}$ pada korpus mandibula sisi kiri kelompok usia 45-54 tahun dan paling rendah yaitu sebesar $15,2 \mathrm{~mm}$ pada korpus mandibula sisi kiri kelompok usia 65-85 tahun.

\section{DISKUSI}

Pada penelitian ini didaptkan data bahwa pasein bergigi lebih banyak dibandingkan korpus mandibula tidak bergigi. Radiograf untuk pengukuran ketinggian korpus mandibula tidak bergigi yang ditemukan di Rumah Sakit Gigi dan Mulut terbatas dalam penelitian ini, maka diambil arsip radiograf populasi pada tahun 2013 dan 2014 Hal ini menunjukkan bahwa pasien tidak bergigi yang datang ke RSGM Unpad untuk perawatan tidak selalu melakukan pengambilan gambar 
radiografi panoramik di Instalasi Radiologi RSGM Unpad. Hasil pengukuran ketinggian korpus mandibula rahang bergigi dari 30 orang laki-laki dan perempuan usia 45 sampai 85 tahun diperoleh data nilai rata-rata hasil pengukuran yang menunjukkan bahwa perempuan memiliki ketinggian korpus mandibula lebih rendah dibandingkan dengan lakilaki usia sama. Hasil pengukuran ketinggian korpus mandibula rahang tidak bergigi dari 20 orang lakilaki dan perempuan usia 45 sampai 85 tahun diperoleh data nilai rata-rata hasil pengukuran yang menunjukkan bahwa perempuan juga memilik ketinggian korpus mandibula tidak bergigi lebih rendah dibandingkan dengan laki-laki usia sama.

Hasil penelitian tersebut sesuai dengan penelitian yang dilakukan Canger dan Celenk pada tahun 2012, dimana didapatkan bahwa nilai ketinggian korpus mandibula perempuan lebih rendah nilainya dibandingkan dengan laki-laki. Penelitian Ural et al., tahun 2011 menunjukkan bahwa nilai rata-rata ketinggian mandibula perempuan lebih rendah dibandingkan laki-laki karena defisiensi hormon estrogen pada perempuan setelah menopause yang mempercepat proses kehilangan tulang. ${ }^{12}$ Berbeda dengan kaum laki-laki, proses menua pada perempuan akan berlangsung lebih cepat dan usia akhir kehidupan seksual perempuan subur adalah pada usia 45-50 tahun, dan pada usia ini siklus menstruasi berhent dan hormon kelamin perempuan berkurang dengan cepat. $^{13}$ Defisiensi estrogen akan menyebabkan terjadinya osteoklastogenesis yang meningkat dan berlanjut dengan kehilangan tulang. ${ }^{14}$

Hasil pengukuran ketinggian korpus mandibula rahang bergigi dan tidak bergigi dari 50 orang lakilaki dan perempuan usia 45 sampai 85 tahun diperoleh data nilai rata-rata hasil pengukuran yang menunjukkan bahwa nilai ketinggian korpus mandibula tidak bergigi pada laki-laki dan perempuan lebih rendah dibandingkan mandibula bergigi. Hasil penelitian tersebut sesuai dengan penelitian yang dilakukan Canger dan Celenk pada tahun 2012 bahwa ketinggian korpus mandibula tidak bergigi lebih rendah dibandingkan mandibula bergigi. Resorbsi tulang meningkat selama satu tahun setelah ekstraksi gigi. ${ }^{5}$

Tulang alveolar mengalami resorbsi dan remodeling setelah mengalami kehilangan gigi, dimana resorbsi tulang alveolar tetap menyisakan struktur mandibula. ${ }^{12}$ Proses remodeling, tulang secara kontinyu mengalami penyerapan dan pembentukan Sel yang bertanggung jawab untuk pembentukan tulang disebut osteoblas, sedangkan osteoklas bertanggung jawab untuk penyerapan tulang. Pembentukan tulang terutama terjadi pada masa pertumbuhan. Pembentukan dan penyerapan tulang berada dalam keseimbangan pada individu berusia sekitar 30-40 tahun. Keseimbangan in mulai terganggu dan lebih berat ke arah penyerapan tulang ketika wanita mencapai menopause dan pria mencapai usia 60 tahun. ${ }^{14}$

Hasil pengukuran ketinggian korpus mandibula rahang bergigi dan tidak bergigi dari 50 orang lakilaki dan perempuan usia 45 sampai 85 tahun yang dibagi ke dalam 3 kelompok usia diperoleh data nilai rata-rata hasil pengukuran yang menunjukkan bahwa tidak terdapat pengurangan ketinggian korpus mandibula yang signifikan seiring dengan pertambahan usia. Hal tersebut karena terdapat beberapa faktor yang tidak dapat ditentukan, antara lain penggunaan dan durasi pemakaian protesa, durasi tiap invidu mengalami kondisi tidak bergigi, dan jarak waktu antara kondisi tersebut sampai pengambilan gambar radiografi.

Menurut data penelitian pada rahang tidak bergigi, ketinggian korpus mandibula laki-laki dan perempuan paling rendah pada kelompok usia 6585 tahun, dan paling tinggi pada laki-laki kelompok usia 55-64 tahun. Menurut Damayanti, 2009 massa tulang menurun sejalan dengan usia. Usia merupakan salah satu faktor yang dapat mempercepat kehilangan tulang. Semakin bertambah usia, semakin besar risikonya karena tulang menjadi berkurang kekuatan dan kepadatannya. ${ }^{15,16}$ Selama masa anak-anak dan dewasa muda, pembentukan tulang jauh lebih cepat dibandingkan dengan kerusakan tulang. Titik puncak massa tulang tercapai pada sekitar usia 30 tahun, dan setelah itu mekanisme resorbsi tulang menjadi jauh lebih cepat dibandingkan dengan pembentukan tulang, namun menurut penelitian Liang et al., 2014 mengenai ketinggian mandibula tidak terdapat perbedaan signifikan antara tiap kelompok usia. Secara keseluruhan hasil penelitian tidak sejalan dengan teori mengenai penurunan ketinggian tulang seiring peningkatan usia. ${ }^{17,18}$ Durasi seseorang mengalami kondisi tidak bergigi dan penggunaan protesa menjadi faktor yang dianggap penting.

Pengukuran vertikal melalui radiograf panoramik dianggap aplikatif untuk pengukuran ketinggian tulang. Keakuratan pengukuran melalui radiograf bergantung kepada kualitas gambar, dimana radiograf digital memiliki kualitas lebih baik. ${ }^{19}$ Penelitian ini memiliki keterbatasan, radiograf yang diambil sebagai sampel dalam penelitian tidak ikut memperhitungkan faktorfaktor lain yang dapat ikut memengaruhi kuantitas tulang rahang seperti obat-obatan yang dikonsumsi, latihan teratur, merokok, konsumsi alkohol, kelainan sistemik, dan lainnya. ${ }^{20}$

\section{SIMPULAN}

Simpulan dari hasil pengukuran ketinggian korpus mandibula pada pasien usia 45 sampai 85 tahun melalui arsip radiograf panoramik digital pada pasien di RSGM Unpad menunjukkan bahwa ketinggian korpus mandibula bergigi sisi kanan paling tinggi adalah pada laki-laki kelompok usia 4554 tahun sedangkan sisi kiri pada laki-laki usia 65-85 tahun, ketinggian korpus mandibula tidak bergigi sisi kanan dan kiri paling tinggi adalah pada laki-laki usia 55-64 tahun, dan secara umum ketinggian korpus mandibula sisi kanan dan kiri perempuan lebih rendah daripada laki-laki pada semua kelompok usia. 


\section{DAFTAR PUSTAKA}

1. White, S.C; M. J. Pharoah. 2009. Oral Radiology Principles and Interpretation. Sixth Edition. Saint Louis: Mosby Elsevier. 96 189.

2. Tortora, G.J; B. Derrickson. 2009. Principles Of Anatomy And Physiology. Twelfth Edition. New Jersey: John Wiley \& Sons, Inc. 72-76.

3. Iannucci, J. M; L. J. Howerton. 2013. Dental Radiography Principles and Techniques. Fourth Edition. Saint Louis: Saunders Elsevier. 270-405

4. Gupta, S; S. Jain. 2012. Orthopantomographic analysis for assessment of mandibula asymmetry. The Journal of Indian Orthodontic Society. 46(1): 33-37. Available online at: 10.5005/jp-journals-10021-1054 (diakses pada 30 November 2014).

5. Canger, E. M; P. Celenk. 2012. Radiographic evaluation of alveolar ridge heights of dentate and edentulous patients. J. Gerodontology, 29: 17-23.

6. Newman, M. G.; H. H. Takei; F. A. Carranza. 2012. Carranza's Clinical Periodontology. Eleventh Edition. Saint Louis: Saunders Company. 316-901.

7. Pedlar, J; J. W. Frame. 2007. Oral and Maxillofacial Surgery. Second Edition. London: Elsevier. 54-151.

8. Ural, C.; C. Bereket; I. Sener; A. M. Aktan; Y. Z. Akpinar. 2011 Bone height measurement of maxillary and mandibular bones in panoramic radiographs of edentulous patients. J Clin Exp Dent. 3(1): 5-9. Available online at: doi:10.4317/jced.3.e5 (diakses pada 15 Februari 2015)

9. Pedersen, P. H.; A. W. G. Walls; J. A. Ship. 2015. Textbook of Geriatric Dentistry. Third Edition. New Jersey: Wiley Blackwell. 41-97.

10. Abdulhadi, L. M. 2008. Prediction the height of maxillary and mandibular alveolar bone in partially and completely edentates: a pilot study. Dentika Dental Journal. 13(1): 24-27
11. Koenig, L.J. 2012. Diagnostic Imaging Oral And Maxillofacial. First Edition. Philadelphia: Amirsys. 81-85

12. Ural C. C Bereket; I. Sener; A. M. Aktan \& Y. Z. Akpinar. 2011. Bone height measurement of maxillary and mandibula bones in panoramic radiographs of edentulous patients. J Clin Exp Dent. 3(1): 5-9. Available online at: doi:10.4317/jced.3.e5 (diakses pada 15 Februari 2015).

13. Sunariani, J. Y. dan B. Aflah. 2007. Perbedaan perseps pengecap rasa asin antara usia subur dan usia lanjut. Majalah Ilmu Faal Indonesia Vol. 6/3/2007. 182

14. Kawiyana, I. K. S. 2009. Osteoporosis patogenesis diagnosis dan penanganan terkini. J Penyakit Dalam. 10(2): 157-170

15. Damayanti, L. 2009. Respon jaringan terhadap gigi tiruan lengkap pada pasien usia lanjut. Makalah. Bandung

16. Utomo, M.; W. Meikawati \& Z. K. Putri. 2010. Faktor-faktor yang berhubungan dengan kepadatan tulang pada wanita postmenopause. J Kesehatan Masyarakat Indonesia, 6(2): 1-9. Available online at: htpp://jurnal.unimus.ac.id (diakses pada 27 Mei 2015)

17. Permana, H. 2010. Patogenesis dan metabolisme osteoporosis pada manula. Makalah. Bandung: Universitas Padjajaran. 1-9.

18. Liang X. H. Y. Kim \& I. Cho. 2014. Residual bone height measured by panoramik radiography in older edentulous Korean patients. The journal of advanced prosthodontics, 6 : 53-59. Available online at: http://dx.doi.org/10.4047/ jap.2014.6.1.53 (diakses pada 7 Februari 2015).

19. Thakur, M.; K. V. K. Reddy; Y. Sivaranjani \& S. Khaja. 2014 Gender determination by mental foramen and height of the body of the mandible in dentulous patients. J Indian Academy Forensic Medical, 36(1): 13-18.

20. Arifin, A. Z.; A. Asano; A. Taguchi; T. Nakamoto; M. Ohtsuka \& K. Tanimoto. 2005. Computer-aided system for measuring the mandibular and cortical width on panoramic radiographs in osteoporosis in osteoporosis diagnosis. Proceedings of the SPIE Medical Imaging 5747, 813-821. 